\title{
ENFERMEDAD, DOLOR Y ESCRITURA EN DOS POEMARIOS DE AUTORAS MEXICANAS: Margarita Paz Paredes y Rocío González
}

\section{Illness, Pain, and Writing in Two Collections of Poems by Mexican Female Authors: Margarita Paz Paredes y Rocío González}

\author{
Gerardo Bustamante-Bermúdez* \\ DOI: https://doi.org/10.29043/liminar.vl8i2.767
}

\begin{abstract}
Resumen: En este artículo se revisa el tema del cáncer a partir de la experiencia autoral que registran las poetas mexicanas Margarita Paz Paredes en Memorias de hospital (1980) y Rocío González en Neurología 211 (2013). Cuestiones como el cuerpo, la memoria, la enfermedad y el tratamiento médico-quirúrgico aterrizan en una escritura del yo para mostrar el límite en el binomio vida/muerte. La escritura en este caso es el recurso para enfrentar la condición de pacientes vulnerables que solo cuentan con la poesía como medio de registro del dolor. Escritura, dolor y enfermedad son una triada indispensable para dejar un testimonio de la relación de las poetas con una enfermedad temida en un tiempo-espacio en donde ambas enfrentan realidades adversas en los que serán sus últimos poemarios.
\end{abstract}

Palabras clave: cuerpo, enfermedad, cáncer, poesía, mujeres poetas, memoria.

Abstract: The theme of cancer is explored in this article, drawing from the authorial experience of two Mexican poets, Margarita Paz Paredes in Memorias de hospital (1980) and Rocío González in Neurología 211 (2013). Themes of the body, memory, illness, and medical-surgical treatment are grounded in writings of the self that illustrate the limits of the life/death duality. Writing is the way the poets confront their situation as vulnerable patients who recount their pain with poetry as their only medium. Writing, pain, and illness are an indispensable triad that underpins a testimony of their relationship with a feared illness in a time-space in which both poets confront adverse realities through their final books of poetry.

Keywords: body, illness, cancer, poetry, women poets, memory.

\footnotetext{
* Gerardo Bustamante Bermúdez. Doctor en Letras por la Universidad Nacional Autónoma de México, México. Profesor-investigador en el Colegio de Humanidades y Ciencias Sociales, Academia de Creación Literaria, de la Universidad Autónoma de la Ciudad de México, México. Temas de especialización: poesía latinoamericana de los siglos XX y XXI, literatura y sociedad, obra poética y dramática de Abigael Bohórquez. Correo electrónico: gerardbb81@hotmail.com. ORCID: https:/orcid. org//0000-0003-4676-8261
}

\author{
Enviado a dictamen: 3 de septiembre de 2019. \\ Aprobación: 20 de enero de 2020. \\ Revisiones: 1.
}


E n su clásico libro de 1977 La enfermedad y sus metáforas, Susan Sontag (2013) analiza la concepción médico-cultural de enfermedades como la sífilis, la tuberculosis y el cáncer a la luz de las connotaciones que la sociedad y la ciencia le dan a estos padecimientos médicos. Si la enfermedad puede ser la antesala de la muerte, existen en la historia de las ideas, e incluso de las religiones, ciertas enfermedades asociadas al castigo divino; otras deben esconderse por vergüenza, como es el caso de la sífilis, el contagio por VIH y algunas más de naturaleza y transmisión sexual.

El cáncer es una de las enfermedades más temidas desde hace varias décadas. Nos informa Sontag que desde la antigüedad se ha definido el cáncer como una excrecencia, bulto o protuberancia y como "un proceso en el que el cuerpo se consumía (2003:23). La imagen contemporánea sobre el cáncer resulta más compleja debido al proceso al que se somete a los pacientes, tanto en procedimientos quirúrgicos como en quimioterapias, radioterapias y otros nuevos tratamientos. Al tratarse de una enfermedad de crecimiento tumoral e invasión, existen tratamientos científicos en los que el sistema inmunológico del paciente debe luchar, muy a pesar del dolor físico y la desestabilización emocional, en contra del crecimiento tumoral. Quien padece cáncer generalmente es visto como un sujeto vulnerable próximo a la muerte. Aunque en la actualidad esa enfermedad no es una sentencia de muerte, el padecimiento se vuelve metáfora dependiendo del lugar del cuerpo en el que se desarrolla, sin embargo, dice Sontag: "El cáncer, que se declara en cualquier parte del cuerpo, es una enfermedad del cuerpo. Lejos de revelar nada espiritual, revela que el cuerpo, desgraciadamente, no es más que el cuerpo" (2013:32). Así pues, nada hay después del cuerpo, sobre todo porque es él el contenedor de las funciones orgánico-biológicas, emocionales y sexuales, de ahí que un cuerpo enfermo es generalmente considerado como incompleto, ya que no cumple a cabalidad con lo que se espera de un sujeto en los ámbitos familiar, laboral y social.
Las enfermedades como el cáncer y los padecimientos crónicos degenerativos suponen condiciones de permanente acompañamiento del dolor provocado por el padecimiento y por las intervenciones médicoquirúrgicas. Un padecimiento o enfermedad se convierte en un acompañante del sujeto que padece. La enfermedad ataca; el paciente trata de defenderse con ayuda de la ciencia, sin embargo, cualquier enfermedad considerada como grave arrastra sentimientos de rabia, soledad y miedo. La enfermedad se convierte en sujeto - se le personifica-; con ella se aprende a luchar y vivir, como en el caso del cáncer.

En su libro, Sontag hace una revisión de algunas enfermedades a través de textos literarios. Dice la autora: "En la Ilíada y en la Odisea, la enfermedad aparece como castigo sobrenatural, como posesión demoníaca o como acción de agentes naturales. Para los griegos la enfermedad podía ser gratuita o merecida (falta personal, transgresión colectiva o crimen cometido por los ancestros" (2013:64). Esta mitología sobre la enfermedad llega a nuestros días cuando la ciencia estudia ciertos tipos de sociedades, genes y alimentación de poblaciones en los que hay mayor número de pacientes diagnosticados con el padecimiento. La autora recupera la noción del cáncer según algunos textos del Romanticismo —de autores como Stendhal, Byron, Novalis y otros - en los que se asocia la represión de sentimientos con el origen de la enfermedad. La enfermedad se convierte en metáfora porque se atribuye la responsabilidad al yo introvertido del paciente; desde esta perspectiva el mismo sujeto es un productor de enfermedades. La enfermedad surge del propio cuerpo y no de agentes externos. Dice Sontag:

Según la mitología, lo que generalmente causa el cáncer es la represión constante de un sentimiento. Es la forma primitiva y más optimista de esta fantasía, el sentimiento reprimido era de orden sexual; ahora, cambio notable, la causa del cáncer es la represión de sentimientos violentos. La pasión frustrada que mató a Insarov era el idealismo. La pasión reprimida que la gente cree que da cáncer es la rabia. No hay Insarovs modernos. Hay en cambio cancerófobos 
como Norman Mailer, que explicó hace poco que de no haber apuñalado a su mujer (dando teatral salida a un "nido de sentimientos asesinos") habría tenido cáncer "muriéndome yo mismo a los pocos años". Es la misma fantasía ligada en otra época a la tuberculosis, sólo que en una versión más sórdida (Sontag, 2013:38).

Estas ideas que pretenden explicar el origen del cáncer a través de la represión de emociones metafóricamente encuentran su explicación en el carácter agresivo con el que actúa la enfermedad en el cuerpo de quienes la padecen; por tal razón, en ocasiones se enuncia que la presencia del cáncer es un autosabotaje del sujeto. Evidentemente, Susan Sontag desestima estas interpretaciones del cáncer como consecuencia de la represión de emociones. Por nuestra parte, lo que interesa es analizar la representación del cuerpo y la enfermedad a través de la obra de dos poetas mexicanas: Margarita Paz Paredes, con Memorias de hospital (1980), y Rocío González, con Neurología 211 (2013), dos textos cuyo tema central es el cáncer desde la experiencia autoral. Aunque distan 33 años entre la publicación de uno y otro, estos poemarios permiten dimensionar el contexto emocional, los avances científicos sobre el tema y, sobre todo, la metáfora de la enfermedad en temporalidades distintas y en textos literarios que quedan como registro autobiográfico y como la experiencia de dos voces líricas en su relación metafórica y real con una enfermedad que aparece en sus vidas como una gran pregunta retórica.

El cáncer indispensablemente - no podría ser de otra manera- está relacionado con la epistemología del cuerpo, y en esta concepción existen una multiplicidad de abordajes desde la ciencia médica, la religión, la filosofía, las ciencias sociales y las humanidades.

En términos generales el concepto cuerpo presenta una lectura biológica y otra biográfica, dicotomía que permite pensar de forma inmediata en una dimensión sexual y otra cultural. Las significaciones culturales y teóricas sobre el cuerpo tienen también una dimensión política, religiosa y social, por lo tanto, la corporalidad de los sujetos presenta significaciones y asignaciones biopolíticas que, al menos en Occidente, tienen la connotación salud/enfermedad, según los parámetros culturales, estéticos, políticos y religiosos. El cuerpo es un concepto complejo de oposiciones binarias que determinan la realización "útil" o "no útil", por ejemplo: cuerpo sano/cuerpo enfermo; cuerpo estético/cuerpo antiestético; cuerpo y mente sana/mente enferma; cuerpo/sexualidadreproducción; cuerpo/trabajo; cuerpo joven/cuerpo viejo, etcétera. El cuerpo está mediado por una red de re-producciones sociales simbólicas y reales en el sentido de que hay un estándar de funcionalidad útil que en el sistema político y social determina a los propios cuerpos, de ahí la angustia del sujeto por ser "desechable" en su medio social cuando la enfermedad se presenta. Como sujetos sociales, las personas estamos determinadas por lo que Pablo Lazo Briones (2010) denomina "políticas de la corporalidad", es decir, las estipulaciones que se hacen alrededor del concepto cuerpo a través de múltiples discursos culturales sobre lo perfecto o aceptable de los sujetos en tanto cuerpos funcionales. Un cuerpo sano es aceptado por útil, un cuerpo enfermo es, por decir lo menos, cuestionado y considerado vulnerable.

Aunque el tema del cuerpo está simbolizado también por aspectos étnicos, estéticos, económicos o políticos, entre otros, existe una red de significaciones intersubjetivas que posibilitan leer los cuerpos desde un territorio práctico y útil. Los sujetos sociales tienen "utilidad" en la medida que responden a exigencias de tipo político, estético, laboral, social y jurídico, pues de acuerdo con Lazo Briones:

Las funciones del cuerpo se explican según regularidades e irregularidades perfectamente estipuladas por la biología en general y por la medicina en particular, se tiene una apreciación estética e higiénica estable, se hacen taxonomías y jerarquizaciones de todo tipo respecto a lo que le es permitido al cuerpo y lo que le es prohibido. Se trata de una valoración anticipada o prevaloración del cuerpo, no sólo por motivos epistémicos, sino [...] por ganancias y rentabilidad social. El cuerpo está mediado por su discursividad cultural (Lazo, 2010:15). 
En el caso de los textos literarios que aquí se analizan, el concepto "cuerpo" se relaciona con el tema de la salud e inevitablemente con el asunto de una enfermedad que termina con la vida de las autoras. Las dos narrativas poéticas sobre la experiencia del cuerpo enfermo a consecuencia del cáncer son mediadas por el lenguaje, porque las dos escritoras mexicanas se expresan desde la subjetividad que proporcionan la experiencia y la temporalidad en las que se padece y trata la enfermedad; una experiencia de desasosiego, ya que el concepto "cuerpo enfermo" es lo único que pueden testimoniar desde una situación límite. Para nombrar y preguntarse sobre su condición corporal, las autoras solo tienen a la mano la poesía, y desde este enfoque es desde donde nos interesa abordar sus obras.

Memorias de hospital (Paz, 2018), de Margarita Paz Paredes (1922-1980), podría considerarse una crónica poética, a la vez que un testimonio de episodios evocados por la autora guanajuatense. Dividido en diez partes y un poema final titulado "Presagio", la voz de Paz Paredes enfatiza el discurso sobre la exploración del cuerpo enfermo en el presente de la enunciación, el balance de su vida y el miedo a lo incierto. Fechado en diciembre de 1979, Memorias de hospital es un libro póstumo de la autora que se publicó en el suplemento dominical El Gallo Ilustrado, del periódico El Día, el 8 de junio de 1980, tres semanas después de la muerte de la poeta y periodista a consecuencia de cáncer. Fue el poeta sonorense Abigael Bohórquez quien entregó al diario el manuscrito que su amiga le había confiado a inicios de enero de 1980. ${ }^{1}$

Este texto resulta un poemario en el que la poeta va descubriendo y nombrando su padecimiento en el espacio frío que es el hospital. De forma paradójica, en ese lugar el binomio vida/muerte se disputa la esperanza por la vida. Los pasillos y habitaciones del nosocomio permiten la evocación del pasado, los amores y la conciencia sobre el ser humano y la memoria. Ese encuentro con el pasado registrado en este libro es una visión subjetiva en la que se captura desde el presente la noción del recuerdo y las emociones significativas dignas de evocarse. El pasado llega al presente de un cuerpo que se anuncia como vulnerable, pero con la lucidez necesaria para entender y reconstruir el pasado en la escritura. El cuerpo está enfermo, pero la mente es un arsenal de recuerdos y preguntas que la autora registra de forma poética.

En "Presagio", dividido en catorce estrofas, la poeta se ubica en el presente de la enunciación, el mes de diciembre. Por la fecha que se marca al final de Memorias de hospital, sabemos que se trata del año 1979. Quizá sea el último poema, al menos de los publicados hasta la fecha, que cierra la vida creativa de Margarita Paz Paredes, por lo tanto puede considerarse como el corolario o apéndice que el lector debe tomar en cuenta al momento de valorar la obra de una mujer enferma que en el invierno de 1979 navega hacia la muerte en medio de esos "innombrables puertos" en los que ella es oleaje y en los que desea recuperar su nombre, después de un proceso de enfermedad y atención médica en el que ha sido un número de cama y una cifra. La confesión poética de Paz Paredes en el que se considera su último texto poético puede entenderse como una invocación a la poesía misma. Es la voz autoral la que desea que la materia poética - y en términos más exactos, la tregua de su agonía- se manifieste, pues ha caído en un abandono poético. La enfermedad ha minado cualquier posibilidad de entrega; la vigilia ha desplazado al sueño y su vida es apagón en una tarde de niebla. Se pregunta la autora:

¿Cómo, entonces, emprender un regreso
para encontrar la ruta
perdida entre la niebla? (Paz, 2018:67).

La enfermedad, como condición humana, hace posible que la voz poética se apague, por eso desde esa "piel dormida" y en vigilia se invoca a la Poesía:
Mi devoción amante ya no alcanza
a descubrir las huellas de tu imagen.
Lejos de mí, distante y muda
en orfandad inmensa me abandonas.

¿En dónde estás, poesía? 
Sola, a la mitad de la noche, yo te invoco (Paz, 2018:68).

En "Presagio", la poeta tiene la seguridad de que va a morir. Llama la atención que a lo largo del poemario no aparezca la palabra "cáncer" ni el lugar del cuerpo en el que habita el tumor. Solo se deduce que se trata de una enfermedad grave de atención urgente. Después de un desgastado proceso de atención médica, con pocos resultados, la escritura del dolor es lo que acompaña la agonía de la autora. El cáncer termina siendo su acompañante, un invasor que se ha adherido al cuerpo. Su condición de enferma le ofrecerá solo dos posibilidades: la recuperación o la muerte, aunque ella sabe que la segunda opción es la segura. Memorias de hospital es un canto poético agónico de una mujer que en sus poemarios anteriores habló sobre el amor, el deseo, la realización y el compromiso con la realidad social. Ahora, desde el preludio final, le pide a la Poesía:

Antes que muera
deja caer en mi silencio
una brizna sonora de tu salterio mágico,
porque será el encuentro
de todo lo anhelado:
el amor y el prodigio,
la esperanza y el sueño,
y en las manos heladas de la muerte
un incendiado trigo de alegría (Paz, 2018:69).

Memorias de hospital es ese salterio mágico en donde las ausencias y la realidad se encuentran en un presente inicialmente cargado de incertidumbre y, después, de certeza. La poeta, insisto, sabe que va a morir, de ahí el título de su poema final. Presagio, según las acepciones de la Real Academia Española significa lo siguiente: "l. m. Señal que indica, previene y anuncia un suceso. 2. m. Especie de adivinación o conocimiento de las cosas futuras por medio de señales que se han visto o de intuiciones y sensaciones" (RAE, 2019). La señal más evidente de la muerte próxima que se muestra en Margarita Paz Paredes es la ausencia de la inspiración o aliento poético para seguir escribiendo. Además del malestar corporal, del que ya no habla en este poema, el presagio es la incapacidad de seguir creando poesía, lo que supone también una sentencia de muerte poética. En cambio, la presencia de la muerte en imágenes que siente próximas resulta la evidencia más clara de su final. Todo lo que simboliza el hospital es sinécdoque de muerte, en su caso.

El libro de la guanajuatense es un recorrido por la incertidumbre que supone una enfermedad tan temida como el cáncer, que invade y se convierte en una lucha entre la voluntad del sujeto y los alcances y limitaciones médicas. Una vez que el cuerpo se siente amenazado y se manifiesta el dolor, llega el momento de la exploración médica, los estudios especializados, la interpretación de los resultados, el diagnóstico y el tratamiento. La casa de la paciente es sustituida por las constantes visitas al hospital. Así, al inicio de su poemario, Margarita Paz Paredes exclama:

\section{iURGENCIAS! iHospital!}

De pronto, arrastrada por un raro dolor entro a este mundo de todos y de nadie, donde estaré quién sabe cuánto tiempo para salir cualquier hora de un día, de pie y hacia la vida o quietamente horizontal y ciega (Paz, 2018:43).

La incertidumbre y el miedo a lo desconocido se advierten por la condición de "urgencia" en un espacio físico que es el hospital y por el miedo a noticias adversas. En la segunda estrofa de la primera parte del poema la autora utiliza ocho sustantivos para remarcar la reflexión alrededor de su condición de enferma que piensa y siente: dolor, muerte, esperanza, indiferencia, miedo, rabia, injusticia y absurdo. Estas palabras se mezclan y confunden en la relación vida/muerte que se siente en el hospital. Del hospital se sale, y se regresa a él, con la frecuencia que la enfermedad lo requiera, por eso en la parte II del poema la autora marca que se trata de un reingreso hospitalario, pero esta vez la voz poética se anuncia en una silla de ruedas, en la sala de urgencias, un día a las seis de la tarde. La voz lírica contempla su condición de enferma y sus dolores, a la 
vez que presenta el dolor de otros, es decir, también es espectadora de los males ajenos. Como si estuviera frente a una escena estática, la poeta dice:
Allí dentro hay un niño de escasos nuevo años.
Me han dejado un instante detenida.
Miro su cuerpecito desnudo y frágil,
como una torre de papel y espuma
próxima a derrumbarse (Paz, 2018:44).

Sobre el niño, la historia queda interrumpida; la poeta no sabe si murió o fue dado de alta, pues ese tipo de historias sin final suelen ser frecuentes entre los pacientes que se encuentran en los nosocomios. En el hospital presentado por Margarita Paz Paredes hay un pabellón para mujeres embarazadas, aquellas que, paradójicamente, darán vida, en medio de la tragedia de otros pacientes que agonizan o mueren. Entre el dolor físico y el cansancio de estas madres, así describe el momento del alumbramiento la poeta:

Breve y escalofriante silencio, cuando el ángel rasga el cristal de su primera morada para lanzarse a un mundo, quién sabe cuán inhóspito, desconocido y sordo (Paz, 2018:46).

A lo largo del poemario es común encontrar la idea de que el ser humano nace para tener un aprendizaje doloroso, sobre todo a partir de que se convierte en adulto. Al contrario que el recién nacido, el crecimiento del sujeto significa una cadena de padecimientos y acechos de la vida misma con todas sus implicaciones. Es a las madres recién paridas a las que: "Les nacen alas mágicas de sus hombros desnudos, / donde los críos implumes encontrarán un nido / vigoroso y seguro" (Paz, 2018:47). No obstante, desde la perspectiva de la autora, solo en el nacimiento y en los primeros años las personas encuentran la protección y la calma. La edad adulta está marcada por peligros y adversidades, es decir, la vida se traduce como una concatenación de acontecimientos adversos.

Al momento de escribir el poemario Margarita Paz Paredes tenía 57 años. Quizá por la experiencia y el proceso doloroso -físico y emocional- en el poemario reaparece la idea de la vida adulta como una condena, por eso en la parte IX del poema habla de un "dolor compañero", como categoría verbal que le sirve para referir solidaridad entre las personas que han padecido alguna operación o están a punto de ingresar al quirófano, espacio temido que se representa como un limbo, en donde la anestesia permite el sueño profundo y la visualización de realidades alteradas y oníricas, sobre todo en el quirófano y la sala postoperatoria, que son lugares de soledad y dolor físico. El silencio se impone, la reflexión sobre la muerte es un asunto individual.

La poeta, mientras recorre los pasillos, observa a las demás pacientes:

Me detengo a la entrada
de cuartos colectivos.
Ellas están tendidas
con su pena obstinada
y nunca se comparten sus soledades solas (Paz,
2018:57).

En esta parte IX del poema, la voz lírica se asume como un lente que observa, que quiere dialogar con el dolor ajeno para terminar con el silencio mortuorio y los estados de inconsciencia de algunas mujeres de edades diversas. Hay un sentimiento de solidaridad y duelo en la voz poética por esos cuerpos que tienen "ausente la mirada, / el dolor derramándose por dentro, y en su noche una herida" (Paz, 2018:58). Como si fuera una cuidadora o una madre sustituta, el yo lírico elige a la más joven:
Aproximo a sus resecos labios
un poco de alimento,
pero ella lo rechaza.
Y oigo su voz quebrada, apenas perceptible:
“-Mañana habrá visita.
Las manos de mi madre
vendrán aquí, sin falta.
Sólo cuando ella llega
vivo, sueño y espero..." (Paz, 2018:58) 
A decir del yo poético, la hora de visita conecta a la persona enferma con los recuerdos y los afectos del mundo íntimo. Frente al espacio cerrado de un hospital, en donde el dolor, la muerte y la despersonalización del sujeto son permanentes, la hora de la visita proporciona un momento de confort. Después viene el silencio y la muerte acechando por los pasillos del hospital, que se describe como sombrío aunque está iluminado.

Porotraparte, hayqueremarcarla despersonalización del sujeto al ingresar a un hospital; el ingreso es la entrada a una "cárcel nocturna" en donde el paciente se convierte solo en un número:

Y me paso la noche con los ojos abiertos y los oídos rotos por órdenes mecánicas: —El “40” al Quirófano. La “32” que grite cuando quiera, porque aún no es tiempo. -Perdón que la interrumpa. La "20" no respira.

- Pues a la Morgue, rápido y sacudan la cama porque hay cola esperando... (Paz, 2018:49).

En medio del ajetreo hospitalario, la voz lírica se aprecia como una mujer "zombie", una "momia" que es conducida por dos enfermeras en una "carroza blanca", en alusión a la camilla de hospital donde la llevan a la sala de operación, mientras el sueño le es inducido por métodos químicos: "Por última vez me miro / flotando bajo una lámpara / de fosforescencias cóncavas (Paz, 2018:51).

El hospital que describe Paz Paredes en un espacio habitado por la soledad y la desesperanza de pacientes que tienen una pena obstinada "y que nunca comparten su soledad a solas" (2018:57). La soledad como experiencia se personifica en el poemario, pues es este sentimiento una suerte de ventana hacia la memoria y el balance de lo que ha sido la vida. El nosocomio es un lugar en donde la esperanza lucha contra la soledad y la catástrofe individual de quien sabe que va a morir.

A lo largo del poemario la autora hace una crónica/ bitácora poética en la que los lectores asistimos a su testimonio y testamento poético. El cuerpo enfermo y la experiencia hospitalaria se registran en la escritura como un modo expedito de comprender la dimensión de la enfermedad y el dolor y también como una conmoción propia de lo que la voz anuncia como su presagio.

\section{II}

En el año 2013, la poeta oaxaqueña Rocío González (1962-2019) dio a conocer Neurología 21l, poemario tremendista dividido en 61 textos en verso o prosa poética en los que la autora también hace la crónica de su estancia hospitalaria en esa relación vida/muerte, a la vez que registra sus recuerdos de infancia y la relación con sus orígenes y afectos en Juchitán, Oaxaca. Al final del poemario aparecen seis textos traducidos al zapoteco por la poeta Natalia Toledo y por Víctor Cata, amigos de González. La traducción de estos poemas, según la nota aclaratoria de Rocío González, "se debe a la necesidad de recuperar una visión, una forma de ser, una manera de habitar el alma ante el tránsito de una vivencia extrema, la que aprendí de mi linaje materno y sus ancestros zapotecas o binnizá" (2013:71).

Desde el título del poemario Rocío González enuncia de forma concreta que se trata de un hospital neurológico eincluso especifica el número de habitación: 21l. El texto es el resultado de una vivencia autoral: el proceso del cáncer, particularmente por el astrocitoma cerebral que desde el año 2011 se le diagnosticó a la autora y que se le atendió en el Instituto Nacional de Neurología, en la Ciudad de México.

Neurología 211 contempla la experiencia hospitalaria y el proceso previo y posquirúrgico con el que la poeta Rocío González tuvo que enfrentarse a partir del diagnóstico. Como en el caso de Paz Paredes, la voz poética se convierte en una cifra, aunque en este caso el tumor sí es nombrado por su nombre científico:

Queda esta cicatriz radiante, pendenciera, antes fuiste tú, astrocitoma: algo querías decirme, todavía no lo sé otras voces hablaron dijeron una cifra turba de fantasmas mientras hacías rondas dentro de mí (González, 2013:7). 
La cicatriz refiere la marca en el cráneo y también la lucha emocional que desencadena en este caso la necesidad de un lenguaje poético para fijar en un discurso la experiencia límite a través de la poesía. A manera de desdoblamiento, la poeta dice: "Miras el espejo, / tu cabeza apenas cubierta de pelo, hermosa, / la marca que pronto se ocultará, / las canas que no conocías, / oscilante entre su salud poderosa/ y el desconcierto sin palabras" (González, 2013:34). La autora manifiesta en este poemario una sostenida preocupación por las palabras, la necesidad por nombrar aquello que se le va revelando, por no olvidar el nombre de los objetos, las personas, la infancia; en síntesis, todo su pasado. Si pierde la memoria y la motricidad, la poesía también se interrumpe.

En términos generales, el tumor cerebral llamado astrocitoma tiene consecuencias como problemas del habla y la visión, cambio de la personalidad e incluso convulsiones, de ahí el interés de la voz lírica por la relación pensamiento/lenguaje/habla en diferentes textos. La cabeza, que es comparada en el poemario con un "dominó revuelto", se afana por conectarse con el cuerpo y sus funciones, sin embargo, se enuncia la posible disfuncionalidad:

dificultad para dormir o para permanecer dormido. movimientos incontrolables de los ojos. movimientos anormales del cuerpo. pérdida de coordinación. confusión. lentitud para pensar. habla torpe. mareos. dolor de cabeza. náuseas. vómitos. estreñimiento. crecimiento del vello no deseado. engrosamiento de los rasgos faciales. agrandamiento de los labios. crecimiento excesivo de las encías. dolor o curvatura del pene (González, 2013:45).

En el poemario, gran parte de la experiencia hospitalaria se construye en el espacio de la cama, que de acuerdo con la simbología alude a un sentido de regeneración, al nacimiento y al placer, según el Diccionario de los símbolos de Jean Chevalier y Alain Gheerbrant, aunque también refiere al lecho fúnebre y a la tierra "que comunica y absorbe la vida" (Chevalier y Gheerbrant, 2012: 633). La cama es un lugar de reposo, de espera, pero en el poemario se observa como un lugar de reflexión, asfixia, dolor y evocaciones de acontecimientos pretéritos. Desde la cama de hospital se generan imágenes y metáforas que más tarde serán poemas.

Para el yo lírico de Neurología 211 el astrocitoma es un fantasma que habita dentro del cuerpo de la poeta. En el proceso de asimilación de la enfermedad, el tumor se convierte en una compañía con la que la poeta está en permanente contacto/conflicto. Una vez que se le ha extirpado el tumor, queda el vacío, que dentro del imaginario poético de la autora es ocupado por luciérnagas. En Neurología 211 la autora recurre a palabras médicas que ahora se incorporan a la nueva vida de la voz que enuncia: tomografía, astrocitoma, signos vitales, meninges, membranas, dentritas, neurocirujano, tumor, respirador artificial, venas, anestesia, masa encefálica, enfermera, neuronas, convulsiones, entre varias otras que se incorporan a la cotidianidad de la poeta y, por tanto, a su poesía. El poemario es un texto que hace referencia a la relación del yo lírico con la enfermedad albergada en la cabeza. En ese sentido es un poemario íntimo, un diálogo de la poeta con su mundo y su padecimiento. Como en el caso de Paz Paredes, Rocío González también fija la fecha de la cirugía y la relación del mundo afectivo de la gente que la rodea:

12 de abril: 12 que convoca la fe de mi mamá.

Me despierto sonriente en la camilla sin promesas, nadie llora, en un abrazo decimos adiós: son Ollin, Adela, Na Nelly, los miro y pido que la vida hable:

(la realidad se expresa en el lenguaje, he repetido cientos de veces) (González, 2013:19).

La lucidez con la que enfrenta la posible pérdida del lenguaje es una preocupación, quizá por eso debe considerarse que Neurología 211 es el último poemario de Rocío González en su oficio de poeta y en su relación entre el "antes" y el "después" de la enfermedad:

soy lo que no soy, lo que nunca seré

la letra que falta: tiemp_

_iempo, ti_mpo,t_empo, tie_po 
son los fuegos mentales

que han empezado a arder (González, 2013:8).

Otro ejemplo de los muchos que se encuentran en el poemario sobre este asunto es la necesidad por nombrar aquello que se tiene miedo de olvidar. El olvido es una forma de muerte; quien no reconoce o no puede nombrar las cosas de la vida está aniquilado para sí mismo y para los otros, por eso la preocupación lírica: "Cientos de sílabas rituales tienen rostro, timbres distintos, bailan cerca de mí, se escinden; a intervalos construyen mi guarida en el 21l, las risas se encaraman sobre ti, te ignoran, en las noches armo papalotes con Leteo" (González, 2013:10). La voz lírica sabe que después de la cirugía el astrocitoma extirpado dejará alguna huella, por eso hay una suerte de desasosiego interior y un continuo periodo de reflexión a través de este poemario que, al igual que en el caso de Margarita Paz Paredes, se convierte en una crónica poética de la estancia hospitalaria. La referencia al personaje de Leteo - también conocido como Lete- alude al río o laguna del Hades, en donde beben las almas de los difuntos para olvidar su vida en el mundo. Es una suerte de rito de purificación mnemotécnica. Según el Diccionario de mitología griega y romana, Lete/Leteo:

significa olvido; era una divinidad nacida de Éride (la Discordia), concebida como una abstracción y hermana de Hipno (el Sueño) y Tánatos (la Muerte). Un río de los Infiernos [...] En las doctrinas que postulaban la reencarnación, las almas purificadas de sus antiguas manchas después de una estancia más o menos larga en los Infiernos, bebían sus aguas para perder todos los recuerdos del mundo subterráneo, que iban a abandonar para entrar en un nuevo cuerpo (Martín, 2001:273-274).

"¿Qué parte de ti fueron mis pensamientos?", se pregunta la voz poética, que siente que el cuerpo es una ramificación sensorial del pensamiento y que, además, la noción sobre el cuerpo sano se centra en la idea médica y social sobre el bienestar. Entre el olvido, el sueño y la muerte hay en la voz poética una necesidad por escribir. A través del lenguaje, Rocío González muestra su preocupación por lo que siente como desnudez lingüística; le habla al astrocitoma antes y después del proceso quirúrgico. Como en el caso de la poeta Paz Paredes, el verbo "sentir" es la expresión a través de la cual la voz lírica desea registrar su experiencia postoperatoria y su deseo por recordar. La sensación que ofrece la siguiente cita es la angustia por saber que la actividad cerebral es correcta incluso en el reconocimiento de las onomatopeyas, los signos y la capacidad de componer imágenes y metáforas que aluden al deseo de protección: "Una oquedad ahora donde estabas me permite sentir actividad en mi cerebro, rechinidos, acomodos, corrientes, ¿oigo? iintuyo? ipercibo? crin, cras, rrrrrrrrr, psssssss, 11lllllllll, gatitos que buscan axilas en la noche fría" (González, 2013:10).

El cuerpo enfermo está ausente de sentido funcional, pero no la mente. De acuerdo con David Le Breton, en los procesos de enfermedad pareciera como si:

la conciencia del cuerpo fuese el único lugar de la enfermedad, y sólo la ausencia definiera la salud. En estas condiciones, uno apenas se atreve a recordar que el cuerpo es, sin embargo, el soporte material, el operador de todas las prácticas sociales y de todos los intercambios entre los sujetos (Le Breton, 1995:122).

Y es que el libro de Rocío González está marcado por la preocupación de hacer funcionar la mente a través del correcto funcionamiento del cuerpo, muy a pesar de la intervención quirúrgica y de lo que viene después: revisiones médicas, quimioterapias, más revisiones que permitan que la persona pueda seguir enunciando su mundo desde su perspectiva que, en este caso, es la poesía y la investigación literaria que la autora ejerció de forma permanente.

La voz emisora en los poemas de Neurología 211 interpela a la enfermedad, que queda personalizada: "sé que algo quieres decirme, todavía no puedo escucharte. cientos de sílabas en mis células dicen leche, música, ronronean y no me atrevo a perturbarlas (González, 
2013:11). La enfermedad es adversaria del lenguaje y el pensamiento en ese "abril de cuatro paredes" que refiere al tiempo de su estancia en el hospital.

A lo largo del poemario se pueden apreciar episodios de tranquilidad en la poeta, después su inquietud y temor por no perder el lenguaje. Las etapas de vigila y de sueño, los estudios médicos, el cuidado de las enfermeras en esa primavera en la que la dejan recorrer los jardines del hospital, acompañada por el recuerdo o la presencia real de Amadeo o María, Adela, Ollin, $\mathrm{Na}$ Nelly y otras personas a las que enuncia, son la crónica de su recuperación y de su manera de volver a tener contacto con los seres, objetos y emociones. Las personas referidas en estricto sentido son su hermano fallecido varios años atrás, una amiga, la hermana de la poeta, su hijo y su nana de la infancia. ${ }^{2}$ Existen en la crónica poética de su estancia en el hospital otros momentos de desasosiego: confiesa dormir para olvidarse del astrocitoma y restarle fuerza al dominio de la enfermedad. En todo momento muestra un miedo por el olvido y la funcionalidad del cerebro para nombrar y reconocer el mundo y su lenguaje:

Eres un pulpo en mi cama y me niego a tus caricias, eres un chiste de mal gusto y me río a pesar tuyo, duermo para olvidarte $y$, sin embargo, tus redes se entretejen en mis lecturas, ávida por saberte, aunque cientos de avispas me picotean en tu nombre, borran las líneas, los acentos, las redondeces de las letras que antes fueron escudo, luces [...] (González, 2013:21).

Cuerpo y mente son temas fundamentales en este poemario. El cuerpo susceptible y entregado a la exploración médica, a los estudios de gabinete, al quirófano y a la cama de hospital es una suerte de resistencia. Si algunas enfermeras la cuidan y protegen, otras muestran una actitud contraria porque no comprenden el dolor físico ni la molestia de los aparatos médicos que auxilian al cuerpo:

el movimiento desprende la sonda de mi uretra, me niego a ponérmela de nuevo, la rabia de la enfermera se acrecienta, se hace la tonta cuando le pido el cómodo, le recuerdo que si orino ella tendrá que cambiar las sábanas, accede y un hilillo de espuma le asoma por la boca (González, 2013:33).

El cuerpo queda a voluntad de la enfermedad y los alcances médicos. La voz poética se entrega a los cuidados de los otros - los familiares y el personal del hospital一, así como a la situación crítica del ataque postoperatorio. Con la claridad de la situación, dice:

la insensata soy yo, ilógica y despierta hago rabiar a la rabiosa enfermera con la que me corresponde pasar este trance; cada cinco minutos el medidor de la presión aprieta mi brazo en forma automática y luego ella viene a medir mi glucosa, a iluminar los iris de mis ojos, a tomar mi pulso: tengo sed, quiero dormir, no me dejan soñar y hago ejercicios de memoria para probar mi lucidez o mi estulticia, canto en mis adentros porque puedo asustar a los enfermos, también porque tengo un respirador artificial que me lo impide. Mis venas todavía inundadas de anestesia juegan con mis pensamientos y floto mientras estoy entera y repito un mantra durante horas, es todo lo que puedo hacer para no dormir, entre memoria y voluntad, y ese deslizarse denso y sensual que me quita la respiración, se activa una alarma, me sacude, no te entregues, alerta (González, 2013:23).

Hay en Neurología 211 una experiencia postoperatoria consciente que muestra el cuerpo de la poeta con dolor y dependiente de cuidados. La mente activa y la necesidad por el lenguaje en su función "correcta" le permiten hacer construcciones de sinestesias y cromatismos, por ejemplo, sueña con playas, escucha y entiende "el idioma del mar"; su cabeza es un jardín. La poeta, dice: "Encapsulo luciérnagas que ocuparán tu espacio" (González, 2013:24), es decir, el del tumor extirpado. Pero también la relación mente/emoción se manifiesta a través de la angustia y la impotencia por episodios de alteración mental: "me entrego a delirios que no sé si son memoria / o amenaza, fruto arcaico que trituro / sin asco y sin deseo. ¿A dónde van mis 
pies" (2013:31). La lucidez tan deseada por la autora, no obstante, es una condición que le provoca angustia, quizá por eso este libro es una necesidad imperiosa por registrar su lucha en un cuerpo que en ocasiones convulsiona. Previo a la operación y después de la intervención quirúrgica, el cuerpo sigue padeciendo los estragos de la enfermedad. La voz lírica repite para no olvidar: "Yo no soy así, yo no soy así, yo no soy así repetía mi cerebro inconsciente mientras el olvido se apoderó de mis horas, icuál es el tiempo perdido que buscamos, Marcel?" (2013:35). Hay en estos versos una conciencia plena por la emboscada de palabras en medio del dolor y la conciencia, por lo que en el fondo la voz lírica sabe que merma la posibilidad de la conciencia. El cáncer invade. Por más que la extirpación del astrocitoma sea una salida científica para detener el tumor, la poeta dice:

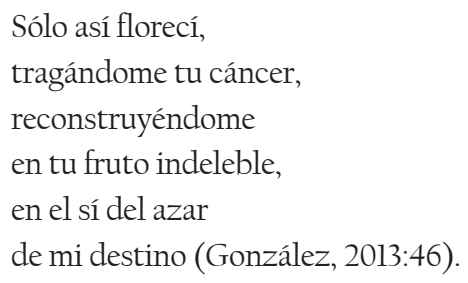

Sólo así florecí, tragándome tu cáncer, reconstruyéndome en tu fruto indeleble, en el sí del azar de mi destino (González, 2013:46).

Al igual que en la obra de Margarita Paz Paredes, en Neurología 211 hay un contacto e interés por el dolor de los demás. El acto de encapsular luciérnagas como recurso de imaginación se traduce en bondad por parte de la voz poética, que le regala las luciérnagas a otra paciente de nombre Sandra, una joven que padece demencia y espera su turno en el quirófano. En un acto de solidaridad, el yo lírico regala su poesía, en este caso, luminosa, como las luciérnagas:

Sandra oscila entre gritos dolorosos y momentos de sedación. Está a mi lado, compartimos enfermera, aunque Sandra no sepa que ésta tiene rabia, a veces le hablo y me sorprende, en su lucidez se concentra en llamar a su mamá.

Encapsulo luciérnagas y se las doy a Sandra (González, 2013:27).
El poema con el que cierra Neurología 211 es una recurrencia al proceso de la cirugía para extraer el astrocitoma cerebral. La poeta utiliza la antítesis frío/ calor para referir la intervención quirúrgica en su relación en el límite vida/muerte. Dice:

A punto de volverme un bloque de hielo,

salgo de mi escondite

sé que he ganado el juego:

iuno, dos, tres por mí y por todos mis amigos!

(González, 2013:69).

La seguridad del triunfo es una evocación a la infancia, a los juegos infantiles y a la posibilidad de respirar de forma libre el encuentro con la vida. Seis años después de la publicación de este poemario tremendista en el que la autora registra su proceso de lucha contra el cáncer, le llegó la muerte el 24 de abril de 2019, pero su poemario queda como una voz resistente, a veces desgarrada, aunque siempre lúcida por la preocupación del lenguaje y la correspondencia entre cuerpo y mente, muy a pesar del regreso del astrocitoma. La posibilidad de enunciar un proceso en el que cuerpo, mente y dolor se funden es un acto de resistencia a través de la poesía. Neurología 211 es una autopsia poética de una voz doliente que lega su resistencia como una manera de enunciarse desde la dignidad y la libertad de las palabras.

\section{III}

Con sus poemarios, Margarita Paz Paredes y Rocío González experimentan una suerte de mutilación o intervención corporal, desde el lenguaje y la biografía de sus emociones, miedos y retos. Es a través del trabajo con las palabras como se produce aparentemente un transitorio reposo y, sobre todo, se afronta una necesidad por traducir en discurso poético aquello que las autoras fijan como una memoria subjetiva de su experiencia en hospitales, con sus correspondientes intervenciones quirúrgicas en situaciones límite entre la vida y la muerte. Una lectura comparativa de estos dos libros permite leer 
algunos datos sobre los avances científicos: en Paz Paredes el tratamiento fue más incipiente, en tanto que en Rocío González se advierten mayores avances científicos a través de una intervención quirúrgica y tratamientos químicos. En ambas se observa una preocupación por el cuerpo y la memoria. La bitácora del dolor, la experiencia y el tiempo aparecen como exploraciones subjetivas que es necesario registrar a través de la poesía porque es una de las sustancias que las ciñe a la vida y a la lucha. Cuerpo, enfermedad y escritura son en estricto sentido la estructura lingüístico-emocional de las autoras frente a un padecimiento temible.

Memorias de hospital y Neurología 211 son el testamento poético de dos poetas mexicanas que sucumben a ese personaje invasivo que es el cáncer, que invade parte de su cuerpo y merma su salud; la enfermedad da alguna tregua a la escritura, luego ataca con mayor virulencia al propio cuerpo. Es a través de la palabra poética de estas dos autoras como los lectores, en términos de Susan Sontag, quedamos mudos "ante el dolor de los demás".

\section{Notas}

${ }^{1}$ Abigael Bohórquez le escribió a su entrañable amiga guanajuatense el poema "Aposento III. Margarita Paz Paredes", incluido en el libro Poesía en limpio (1979-1989) (Bohórquez, 1990:92-94).

2 Agradezco a la novelista y crítica literaria Adriana González Mateos, amiga de Rocío González, por proporcionarme la identidad de estas personas que aparecen en el poemario y que resulta necesario reconocer porque son parte de la biografía emocional de la autora del poemario al momento de su lectura.

\section{Referencias}

Bohórquez, Abigael (1990). Poesía en limpio (1979-1989). México: Universidad de Sonora.

Chevalier, Jean y Alain Gheerbrant (2012). Diccionario de los símbolos. Barcelona: Herder.

González, Rocío (2013). Neurología 211. México: Trilce Ediciones/Comisión Nacional para el Desarrollo de los Pueblos Indígenas.

Lazo Briones, Pablo (2010). "Introducción. Corporalidad, políticas y representación”. En Pablo Pazo Briones y Maya Aguiluz Ibargüen (coords.), Corporalidades. México: Universidad Nacional Autónoma de México/ Centro de Investigaciones Interdisciplinarias en Ciencias y Humanidades/Universidad Iberoamericana.

Le Breton, David (1995). Antropología del cuerpoy modernidad. Buenos Aires: Ediciones Nueva Visión.

Martín, René (2001). Diccionario de mitología griegay romana. Madrid: Espasa-Calpe.

Paz Paredes, Margarita (2018). Memorias de hospital. Introducción de Jocelyn Martínez Elizalde y Diego Alcázar Díaz. México: Archivo Negro de la Poesía Mexicana.

RAE (Real Academia Española) (2019). Diccionario de la lengua española. Madrid: RAE. Disponible en: https:// dle.rae.es/.

Sontag, Susan (2013). La enfermedad y sus metáforas. El siday sus metáforas. México: Punto de Lectura. 